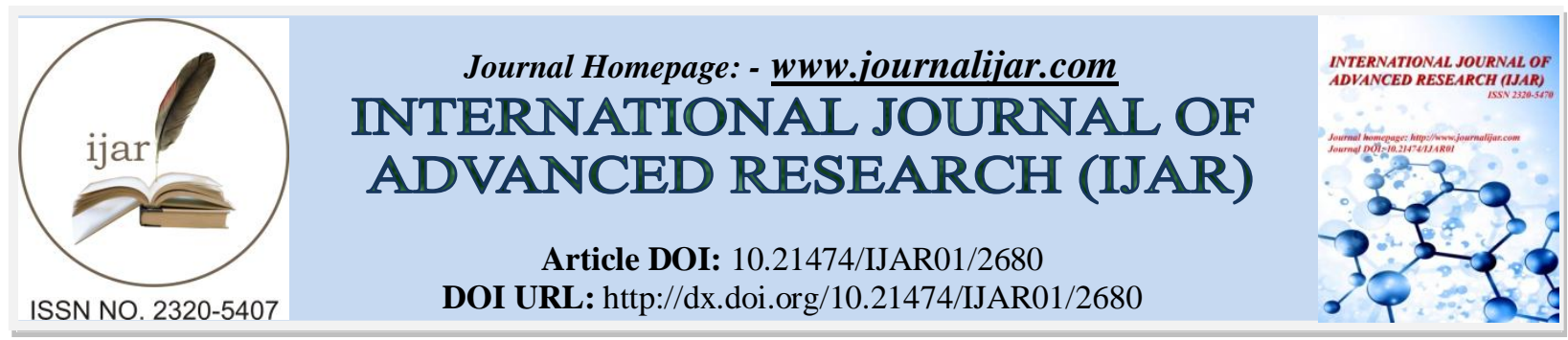

RESEARCH ARTICLE

\title{
CORROSION INHIBITION OF PURE ZINC IN 2.5 M HF ACID SOLUTION BY USING ORGANIC AND INORGANIC SALTS.
}

Azza El-Sayed El-Shenawy.

Chemistry Department, Faculty of Science, Al-Azhar University.

\section{Manuscript Info}

Manuscript History

Received: 31 October 2016

Final Accepted: 01 December 2016

Published: December 2016

Key words:-

Pure $\mathrm{Zn}, \mathrm{HF}$, Organic salts, Inorganic

salts.

\section{Abstract}

Corrosion inhibition of pure Zinc in $2.5 \mathrm{M} \mathrm{HF}$ acid by using organic and inorganic salts such as Tri-sodium citrate, Potassium hydrogen phthalate, Sodium oxalate, Potassium dihydrogen ortho phosphate and Potassium dichromate was investigated using open circuit measurements, potentiodynamic polarization and surface examination via scanning electron microscope (SEM) techniques. The percentage of inhibition efficiency was found to increase with increasing the concentration of Tri-sodium citrate, Potassium dihydrogen ortho phosphate and Potassium dichromate but decrease with increasing the concentration of the other salts, such as Potassium hydrogen phthalate and Sodium oxalate salts. Results revealed clearly that, open circuit measurements and potentiodynamic polarization are in agreement. Analyses of the surface by scanning electron microscope (SEM) technique confirm these results.

Copy Right, IJAR, 2016,. All rights reserved.

\section{Introduction:-}

Pure zinc and its alloys are widely used and the dosage of zinc is the fourth most consumed metal, merely less than iron, aluminum and copper. Zinc is extensively used for coating or galvanizing ferrous metal products due to its better resistance to atmospheric corrosion than carbon steel. In most atmospheric environments, zinc has high corrosion resistance due to the formation ofa protective layer consisting of a mixture of zinc oxide, zinc hydroxide and various basic salts depending on the nature of the environment [1-2]. Zinc metal is highly susceptible to attack by acids and it is a favorable anode in primary batteries, high discharge efficiency and high safety features associated with its manufacturing processes and uses. The dissolution rate of zinc in acids is greatly affected by the overpotential of hydrogen evolution at cathodic inclusions. The behavior of metals and alloys in aggressive media depends on many factors such as the chemical composition, the stability of the oxide film, metallurgical and processing parameters, and the effectiveness of any applied protection [3]. The corrosion behavior of metals in hydrofluoric acid has not been as systematic studied in the laboratory as for other common inorganic acids. This is largely because tests using hydrofluoric acid cannot be run in standard equipments and because of toxic nature of this acid. One of the reasons is because hydrofluoric acid commonly attacks the coupons used for testing in a nonuniform manner. That is, the corrosive power of this acid is not aimed to uniform thinning but mostly to localized penetration below the skin of the metals in the form of thin cracks, voids, pits, trenches and sometimes inter-granular attack [4]. Because of the industrial applications of zinc, inhibition of its corrosion is of considerable importance. The use of chemical inhibitors to decrease the rate of corrosion process is quite varied. In the oil extraction and processing industries, inhibitors have always been considered to be the first line of defense against corrosion [5]. Inhibitors are chemicals that react with a metallic surface, or the environment, this surface is exposed to, giving the 
surface a certain level of protection and often work by adsorbing themselves on the metallic surface or protecting the metallic surface by forming a film and normally distributed from a solution or dispersion [5]. The use of inhibitors is one of the most practical methods for protection against corrosion, especially in acidic media [6]. The effect of some organic and inorganic compounds on the corrosion of zinc in $35 \%$ hydrofluoric acid has been studied by Pogrebova and associates [7]. The inhibiting action of tri-bezyl amine, tri-isoamyl amine, tiphen and sulphanol on zinc was found to increase in the order : sulphuric acid < hydrofluoric acid < hydrochloric acid < hydrobromic acid [8]. Abd El Haleem and Abd Fattah [9] have studied the corrosion behavior of zinc in solutions of the sodium salts of formate, acetate, propionate, citrate, tartrate, oxalate and benzoate anions.

The object of this study is to investigate the inhibition effect of various salts on the corrosion of pure zinc in hydrofluoric acid solution.

\section{Experimental and Methodology:- \\ Materials and solutions:-}

The zinc used was spectroscopically pure ( purity, 99.9\%). Research grade reagents were employed where possible. All aerated test solutions were prepared from deionized water at room temperature $\left(25 \pm 1{ }^{\circ} \mathrm{C}\right)$. The electrode to the solution was $0.5 \mathrm{~cm}^{2}$. Before each experiments, the electrode were successively polished with 800,1000 and 1200 grade emery papers then thoroughly cleaned with distilled water, acetone and finally with doubly distilled water. The counter electrode was platinum and the reference electrode was $\mathrm{Ag} / \mathrm{AgCl}$ coupled to a Luggin capillary. The electrolyte cell used made from Pyrex glass, $50 \mathrm{ml}$ of the test solution were used. Organic and inorganic salts such as tri-sodium citrate, potassium hydrogen phthalate, sodium oxalate, potassium dihydrogen ortho phosphate and potassium dichromate tested as inhibitors. The concentration range of inhibitors was $1 \times 10^{-1} \mathrm{M}$ to $5 \times 10^{-3} \mathrm{M}$ except in case of potassium hydrogen phthalate was $7 \times 10^{-2} \mathrm{M}$ to $5 \times 10^{-3} \mathrm{M}$. The aggressive solution of $2.5 \mathrm{M} \mathrm{HF}$ was prepared by dilution of analytical grade $40 \% \mathrm{HF}$ with deionized water.

\section{Open circuit measurements and Polarization measurements:-}

Open circuit potential measurements and potentiodynamic polarization measurements were performed on computerized potentiostat (Radiometer model Volta Lab 40) and VoltaMaster 4 software. The potentiodynamic curves were recorded by varying the electrode potential automatically from -1500 to $+1500 \mathrm{mV}_{(\mathrm{Ag} / \mathrm{AgCl})}$ with scan rate of $2 \mathrm{mVs}^{-1}$.

\section{Scanning Electron Microscope analysis:-}

Surface analysis of zinc electrode before and after the potentiodynamic polarization test was carried out by scanning electron microscope model Quanta 250 FEG (field Emission Gun) attached with EDX Unit, with accelerating voltage $30 \mathrm{KV}$.

\section{Results and Discussion:- \\ Open circuit measurements:-}

One of the simplest qualitative methods to study the corrosion behavior of metals is the measurements of open circuit potential (OCP) in time. The open circuit potentials of pure zinc electrode as a function of time in aerated solutions of 2.5 M HF containing different concentrations of organic and inorganic salts are followed till the steady state values $\left(\mathrm{E}_{\mathrm{s.s}}\right)$ are reached. A rise in potential in the positive direction indicates the formation of passive film, and a steady potential indicated that the film remains protective.

The extent of rise $\left(\mathrm{E}_{\mathrm{s} . \mathrm{s}}\right)$ becomes more noble in more concentrated solutions in case of tri-sodium citrate, potassium dihydrogen ortho phosphate and potassium dichromate, while in case of potassium hydrogen phthalate and sodium oxalate, the value of $\left(\mathrm{E}_{\mathrm{s} . \mathrm{s}}\right)$ becomes more noble in more diluted solutions. As is clear from the results, the potential shift towards less negative values due to the presence of a protective oxide film on the pure zinc [5]. The immersion potential $\left(\mathrm{E}_{\mathrm{im}}\right)$ as well as steady state potential for each experiment run is listed in Tables $(1,2)$.

Tables (1), illustrate the values of $\left(\mathrm{E}_{\mathrm{s} . \mathrm{s}}\right)$ becomes more noble in more concentrated solutions, while Tables (2), illustrate the values of $\left(\mathrm{E}_{\mathrm{s.s}}\right)$ becomes more noble in more diluted solutions. 
Table 1:- Values of $\left(\mathrm{E}_{\mathrm{im}}\right)$ and $\left(\mathrm{E}_{\mathrm{s} . \mathrm{s}}\right)$ for the pure zinc electrode in $2.5 \mathrm{M} \mathrm{HF}$ containing different concentrations of tri-sodium citrate, potassium dihydrogen ortho phosphate and potassium dichromate at room temperature

\begin{tabular}{|c|c|c|c|}
\hline Inhibitors & Concentration & $\left(\mathrm{E}_{\text {im }}\right) \mathrm{mV}$ & $\left(\mathrm{E}_{\mathrm{s.s}}\right) \mathrm{mV}$ \\
\hline Blank (HF) & $2.5 \mathrm{M}$ & -952 & -948 \\
\hline & $5 \times 10^{-3} \mathrm{M}$ & -941.55 & -364.38 \\
Tri-sodium citrate & $5 \times 10^{-2} \mathrm{M}$ & -404.97 & -352.63 \\
& $1 \times 10^{-1} \mathrm{M}$ & -687.08 & -535.98 \\
\hline \multirow{3}{*}{ Potassium dihydrogen ortho phosphate } & $5 \times 10^{-3} \mathrm{M}$ & -954.21 & -939.54 \\
& $5 \times 10^{-2} \mathrm{M}$ & -947.59 & -920.10 \\
& $1 \times 10^{-1} \mathrm{M}$ & -939.26 & -906.01 \\
\hline \multirow{2}{*}{ Potassium dichromate } & $5 \times 10^{-3} \mathrm{M}$ & -929.35 & -895.70 \\
& $5 \times 10^{-2} \mathrm{M}$ & -683.90 & -743.30 \\
& $1 \times 10^{-1} \mathrm{M}$ & -614.70 & -603.90 \\
\hline
\end{tabular}

Table 2:- Values of $\left(\mathrm{E}_{\mathrm{im}}\right)$ and $\left(\mathrm{E}_{\mathrm{s} . \mathrm{s}}\right)$ for the pure zinc electrode in $2.5 \mathrm{M} \mathrm{HF}$ containing different concentrations of potassium hydrogen phthalate and sodium oxalate at room temperature

\begin{tabular}{|c|c|c|c|}
\hline Inhibitors & Concentration & $\left(\mathrm{E}_{\mathrm{im}}\right) \mathrm{mV}$ & $\left(\mathrm{E}_{\mathrm{s.s}}\right) \mathrm{mV}$ \\
\hline Blank (HF) & $2.5 \mathrm{M}$ & -952 & -948 \\
\hline Potassium hydrogen phthalate & $5 \times 10^{-3} \mathrm{M}$ & -608.21 & -472.14 \\
& $5 \times 10^{-2} \mathrm{M}$ & -593.44 & -493.31 \\
& $7 \times 10^{-2} \mathrm{M}$ & -682.59 & -526.84 \\
\hline Sodium oxalate & $5 \times 10^{-3} \mathrm{M}$ & -253.40 & -693.53 \\
& $5 \times 10^{-2} \mathrm{M}$ & -538.19 & -771.26 \\
& $1 \times 10^{-1} \mathrm{M}$ & -915.69 & -881.90 \\
\hline
\end{tabular}

Figures [1-3], illustrate the case I while figures [4-5], illustrate the case II. Figures [1-3] represent typical curves of variation of OCP with time of zinc for $2.5 \mathrm{M} \mathrm{HF}$ (blank) and inhibited solutions (tri-sodium citrate, potassium dihydrogen ortho phosphate and potassium dichromate) during $90 \mathrm{~min}$. Steady state potential is shifted either in the positive direction in the presence of inhibited salts. The OCP shift in the noble direction, suggests the formation of a passive film that act as a barrier for metal dissolution and reduces the corrosion rate [5]. Furthermore, figures [4-5], illustrate variation of OCP with time of zinc for $2.5 \mathrm{M} \mathrm{HF}$ (blank) and inhibited solutions (potassium hydrogen phthalate and sodium oxalate ) during $90 \mathrm{~min}$. Introduction of these inhibited salts into the acid solution, steady state potential is shifted either in the positive direction and become more nobler than that in the blank solution, that attributed to the formation of a protective layer of these compounds on the zinc surface. In case of sodium oxalate (diluted solution), OCP is shifted positively first and then decreased quickly to reach steady state value, on the other hand, OCP in case of potassium hydrogen phthalate, increased quickly to approach relatively steady state values.

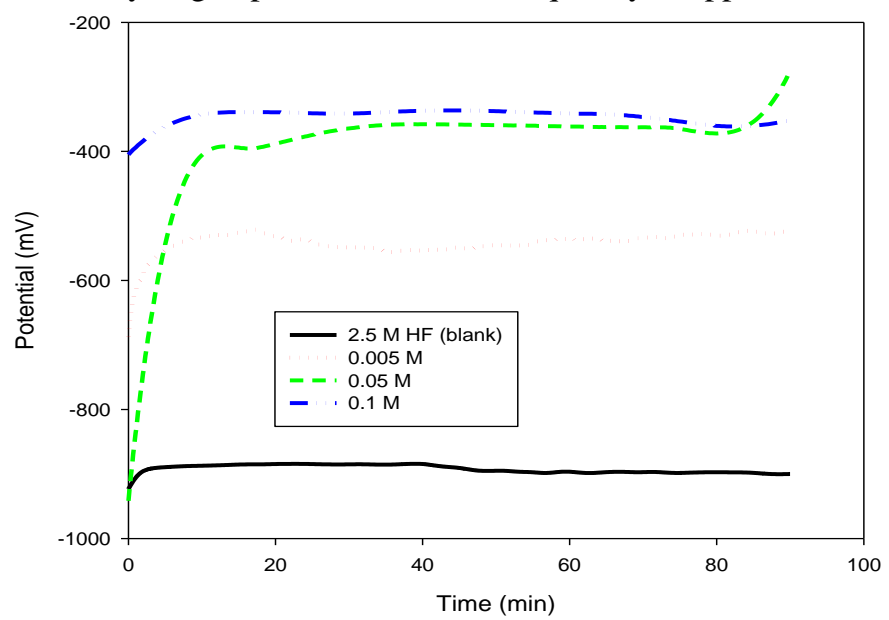

Fig 1:- Variation of open circuit potential of pure zinc in $2.5 \mathrm{M}$ HF solution in the absence and presence of different concentrations of Tri-sodium citrate at room temperature 


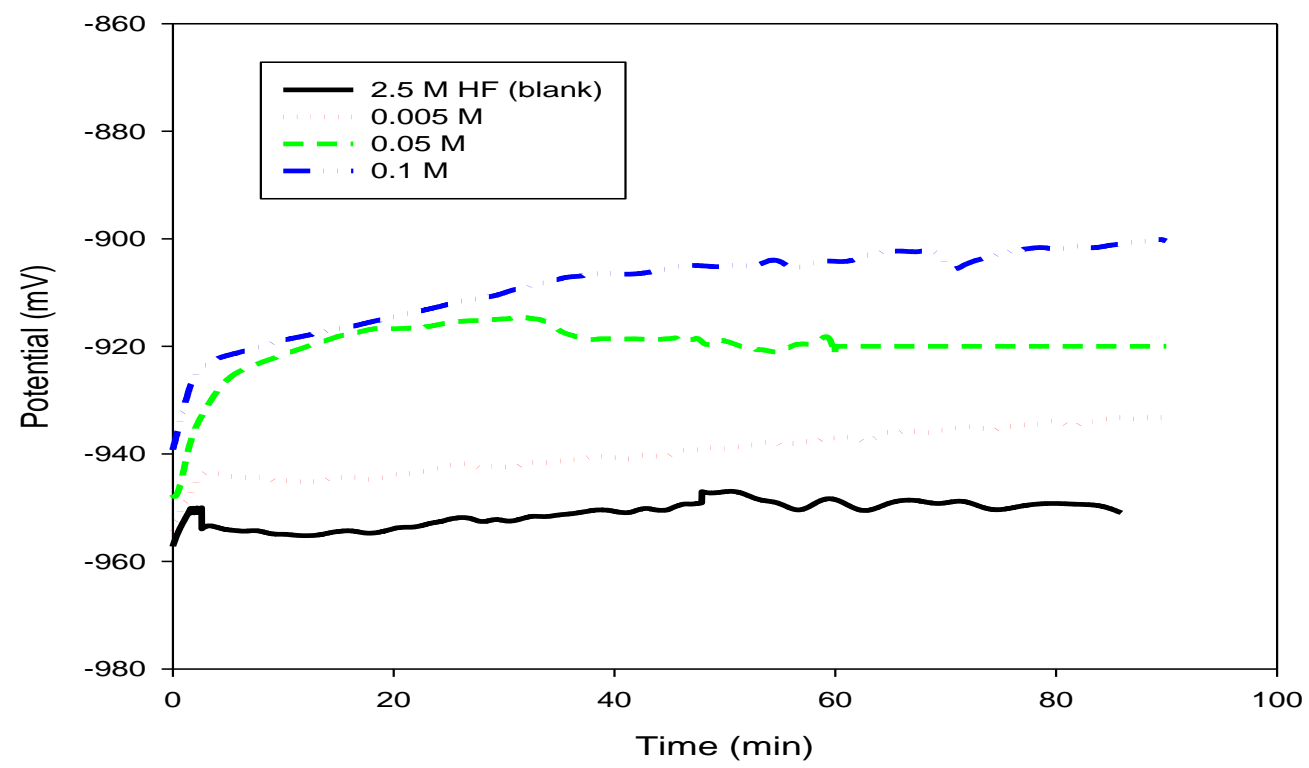

Fig 2:- Variation of open circuit potential of pure zinc in $2.5 \mathrm{M} \mathrm{HF}$ solution in the absence and presence of different concentrations of Potassium dihydrogen ortho phosphate at room temperature.

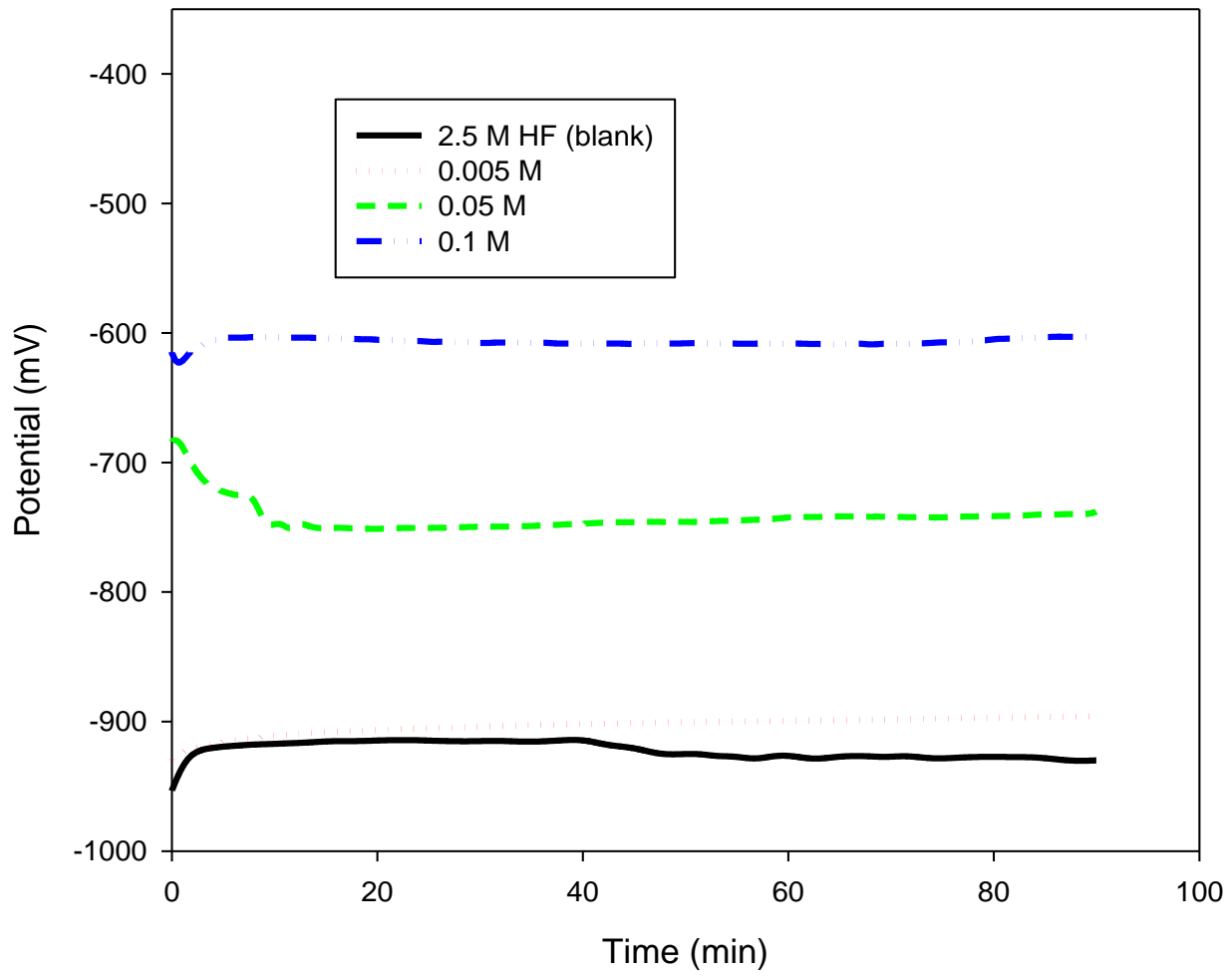

Fig 3:- Variation of open circuit potential of pure zinc in $2.5 \mathrm{M} \mathrm{HF}$ solution in the absence and presence of different concentrations of Potassium dichromate at room temperature. 


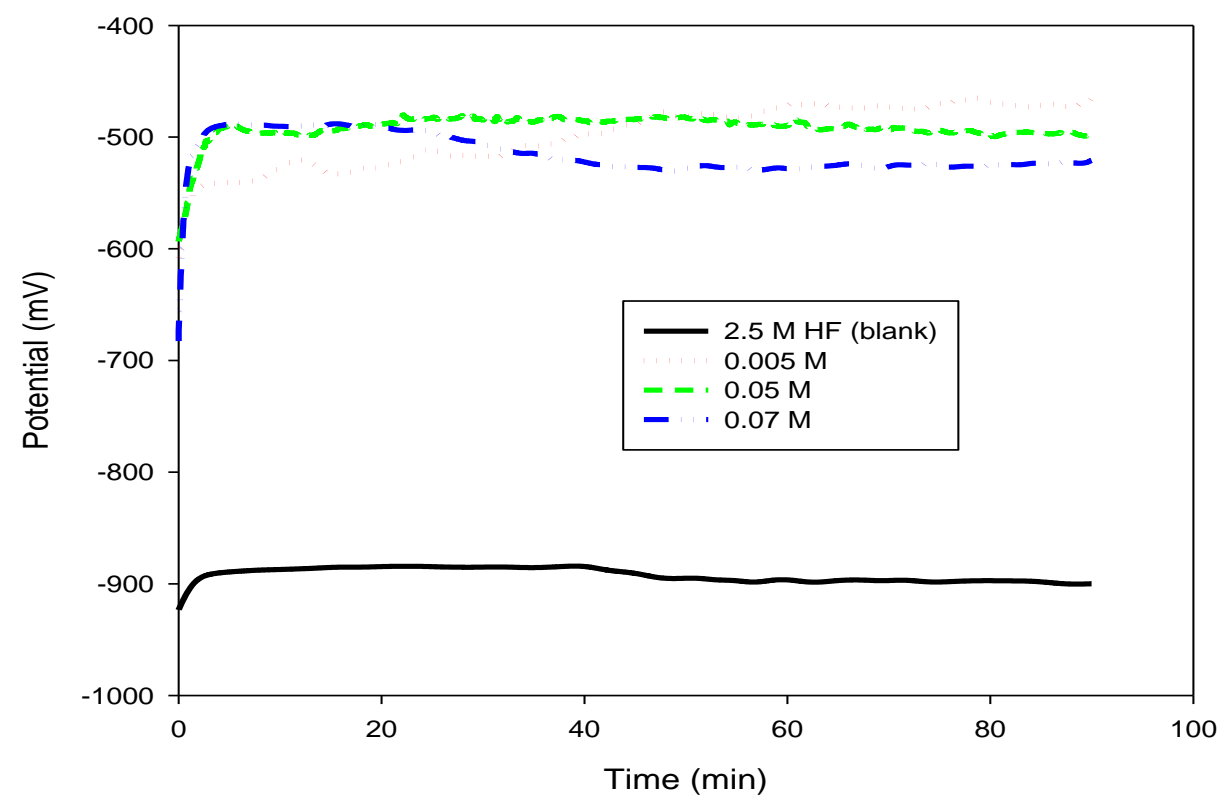

Fig 4:- Variation of open circuit potential of pure zinc in $2.5 \mathrm{M} \mathrm{HF}$ solution in the absence and presence of different concentrations of Potassium hydrogen phthalate at room temperature.

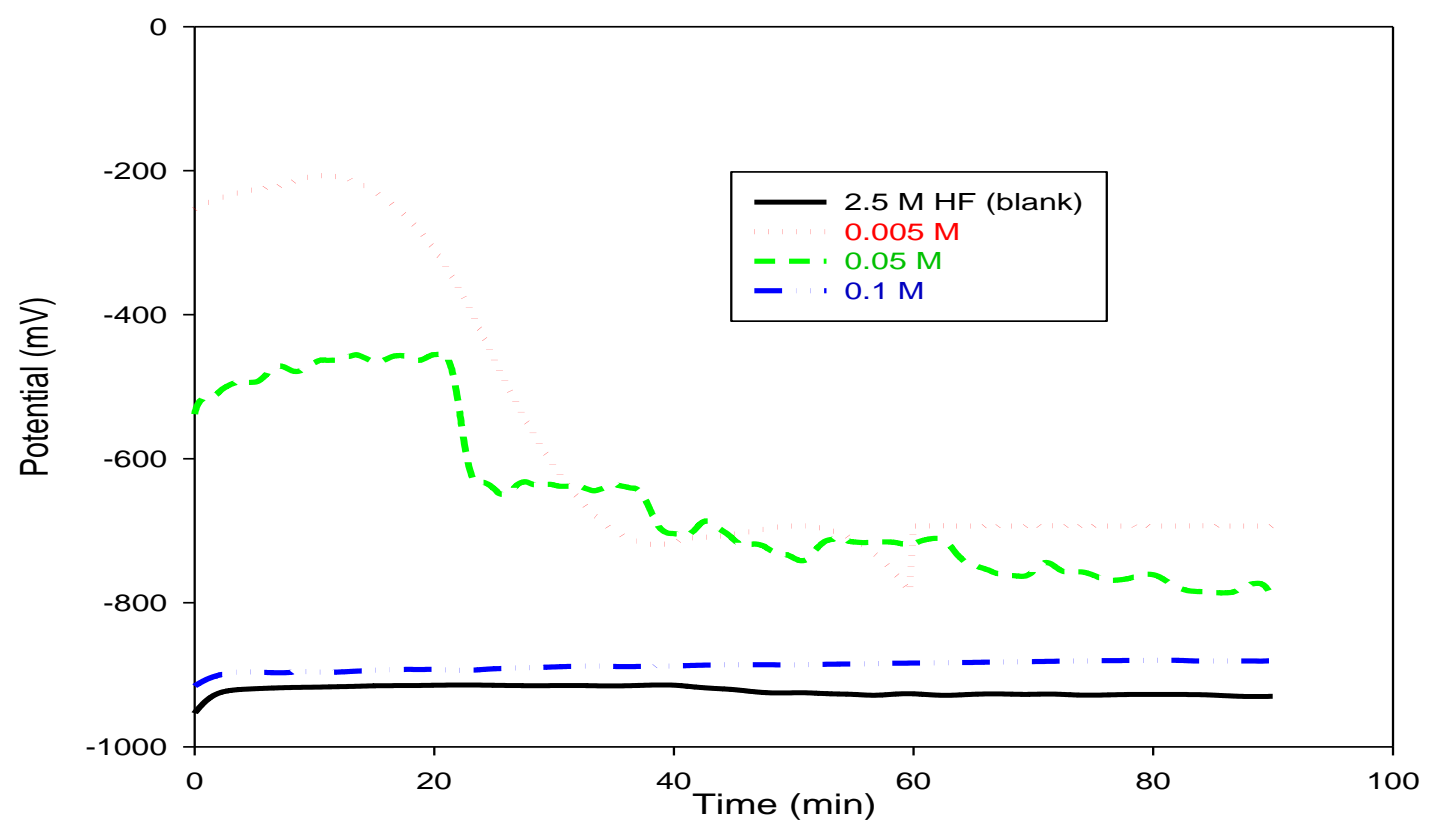

Fig 5:- Variation of open circuit potential of pure zinc in 2.5 M HF solution in the absence and presence of different concentrations of Sodium oxalate at room temperature

\section{Potentiodynamic polarization measurements:-}

The use of chemical inhibitors to slow corrosion processes by increasing the anodic or cathodic polarization behavior or reducing the movement or diffusion of ions to the metallic surface or increasing the electrical resistance of the metallic surface. Inhibitors of corrosion in acid solution can interact with metals and affect the corrosion reaction in a number of ways, some of which may occur simultaneously. The predominant mechanism of action of an inhibitor may vary with factors such as its concentration, the $\mathrm{pH}$ of the acid, the nature of the anion of the acid, the presence of other species in the solution, the extent of reaction to form secondary inhibitors, and the nature of the metal. In acid solutions the anodic process of corrosion is the passage of metal ions from the oxide-free metal 
surface into the solution, and the principle cathodic process is the discharge of hydrogen ions to produce hydrogen [5].

Hydrofluoric acid is classified as a weak acid because of its lower dissociation constant compared to the strong acids. It ionizes in aqueous solution in a similar fashion to other common acids. HF is the only hydrohalic acid that is not considered a strong acid, i.e. it does not fully ionize in dilute aqueous solutions [10].

$\mathrm{HF}+\mathrm{H}_{2} \mathrm{O}=\mathrm{H}_{3} \mathrm{O}^{+}+\mathrm{F}^{-} \quad$ reaction (1)

Hydrofluoric acid readily react with many metals to form metallic fluoride film, which depending upon conditions, may be thin adherent and protective to further reaction [11].

\section{Effect of Tri-sodium citrate, Potassium dihydrogen ortho phosphate and Potassium dichromate on the} corrosion behavior of pure Zinc in hydrofluoric acid:-

Inorganic inhibitors usually crystalline salts such as sodium chromate, phosphate, or molybdate. Only the negative anions of these compounds are involved in reducing metal corrosion [12].

Organic inhibitors usually designated as film-formation protect the metal by forming a hydrophobic film on the metal surface. Their effectiveness depends on the chemical composition, their molecular structure and their affinities for the metal surface [5].

The corrosion characteristics of pure zinc metal in 2.5 M HF in presence of different concentrations of tri-sodium citrate, potassium dihydrogen ortho phosphate and potassium dichromate were obtained by electrochemical $\log$ current - potential curves ( figures 6 - 8). The corrosion potential $\mathrm{E}_{\text {corr. }}$, corrosion current densities $\mathrm{i}_{\text {corr. }}$, corrosion rate and inhibition efficiencies \% IE were listed for each experiment in Table (3). Inhibition efficiency was calculated from Stern-Geary equations [13] given below:
$\% \mathrm{IE}=\left[\mathrm{i}_{\text {corr.- }} \mathrm{i}_{\text {corr.(inh. }} / \mathrm{i}_{\text {corr. }}\right] \times 100$
equation (1)
$\% \mathrm{IE}=\left[\mathrm{R}_{(\text {inh.). }} \mathrm{R} / \mathrm{R}_{\text {(inh.) }}\right] \times 100$
equation (2)

Generally with increasing inhibitors concentration, the corrosion current density and corrosion rate decrease, while $\%$ IE increases Table (3).

Table 3:- Corrosion parameters for the pure zinc electrode in $2.5 \mathrm{M} \mathrm{HF}$ containing different concentrations of trisodium citrate, potassium dihydrogen ortho phosphate and potassium dichromate at room temperature.

\begin{tabular}{|c|c|c|c|c|c|c|c|}
\hline Inhibitors & Concentration & $\mathrm{E}_{\text {corr. }} \mathrm{mV}$ & $\mathrm{i}_{\text {corr. }} \mathrm{mA} / \mathrm{cm}^{2}$ & $\beta_{\mathrm{a}}$ & $\beta_{\mathrm{c}}$ & $\mathrm{C} . \mathrm{R} \mathrm{mm} / \mathrm{y}$ & $\% \mathrm{IE}$ \\
\hline Blank (HF) & $2.5 \mathrm{M}$ & -818.0 & 2.2044 & 92.3 & -98.3 & 25.61 & --- \\
\hline Tri-sodium citrate & $5 \times 10^{-3} \mathrm{M}$ & -822.5 & 1.760 & 63.5 & -159.2 & 20.45 & 20.1 \\
& $5 \times 10^{-2} \mathrm{M}$ & -908.1 & 1.197 & 75.5 & -105.4 & 13.91 & 45.6 \\
& $1 \times 10^{-1} \mathrm{M}$ & -460.8 & 0.4245 & 99.4 & -102.0 & 4.933 & 80.7 \\
\hline Potassium & $5 \times 10^{-3} \mathrm{M}$ & -870.1 & 1.0865 & 97.1 & -100.7 & 12.62 & 50.7 \\
dihydrogen ortho & $5 \times 10^{-2} \mathrm{M}$ & -888.4 & 0.7341 & 89.1 & -104.9 & 8.531 & 66.6 \\
phosphate & $1 \times 10^{-1} \mathrm{M}$ & -866.0 & 0.4001 & 85.4 & -90.7 & 4.649 & 81.8 \\
\hline Potassium & $5 \times 10^{-3} \mathrm{M}$ & -843.2 & 1.7161 & 90.5 & -100.8 & 19.94 & 22.1 \\
dichromate & $5 \times 10^{-2} \mathrm{M}$ & -662.1 & 0.6630 & 78.8 & -130.0 & 7.70 & 69.9 \\
& $1 \times 10^{-1} \mathrm{M}$ & -575.8 & 0.5114 & 76.0 & -97.5 & 5.943 & 76.7 \\
\hline
\end{tabular}




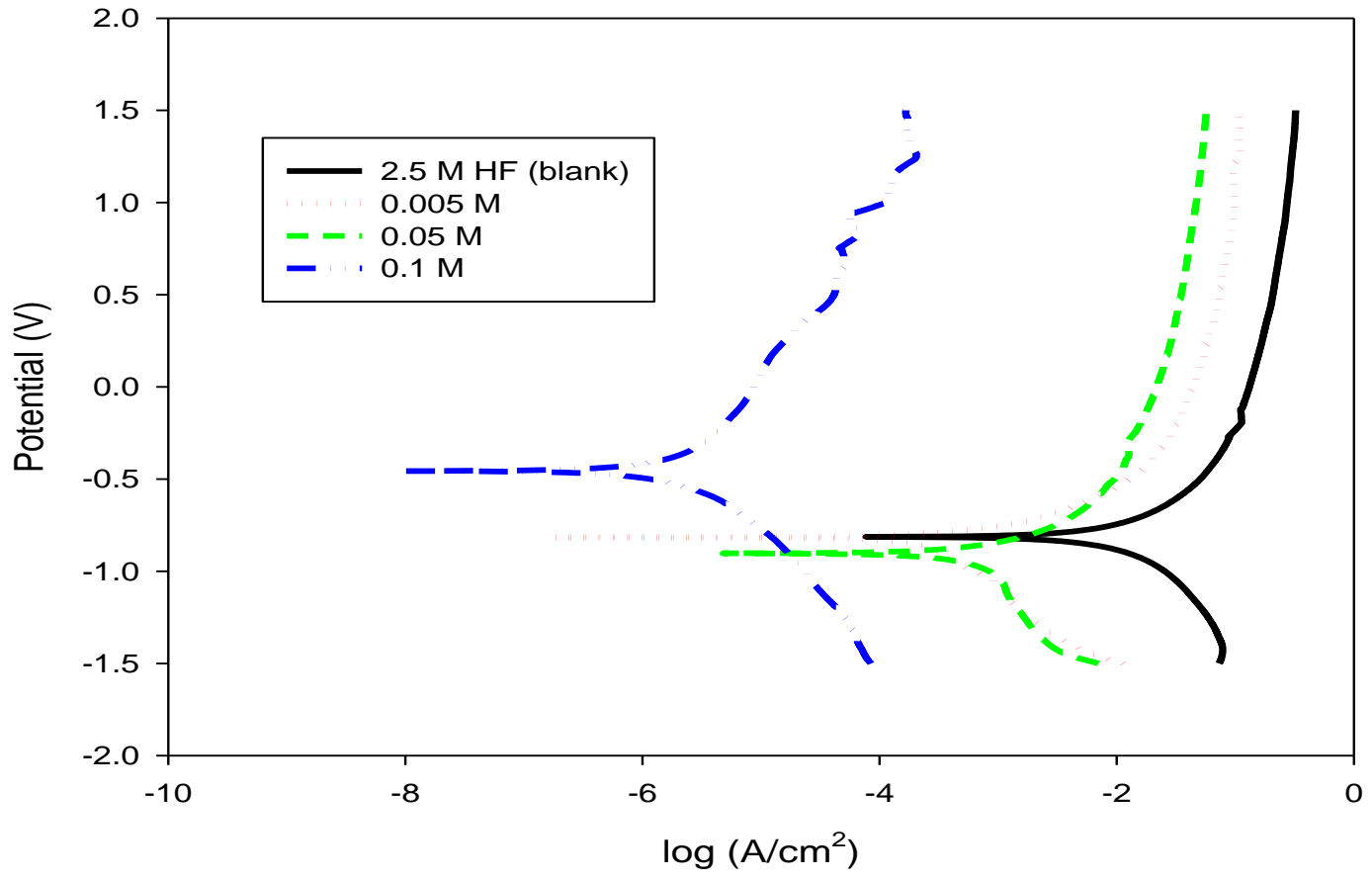

Fig 6:- Anodic and cathodic potentiodynamic polarization curves for pure Zinc in $2.5 \mathrm{M}$ HF solution in the absence and presence of different concentration of Tri sodium citrate at room temperature.

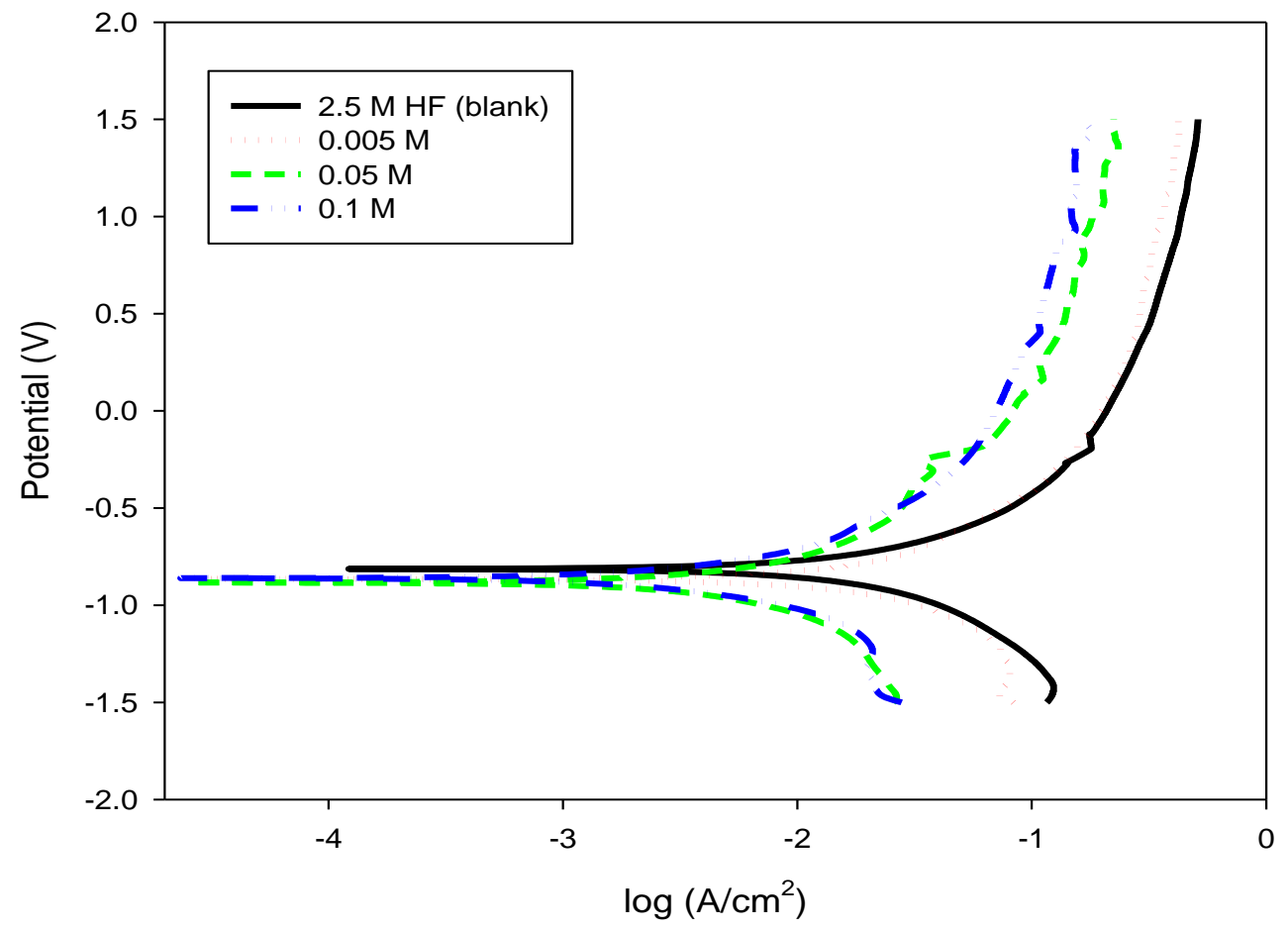

Fig.7:- Anodic and cathodic potentiodynamic polarization curves for pure Zinc in $2.5 \mathrm{M}$ HF solution in the absence and presence of different concentration of Potassium dihydrogen ortho phosphate at room temperature. 


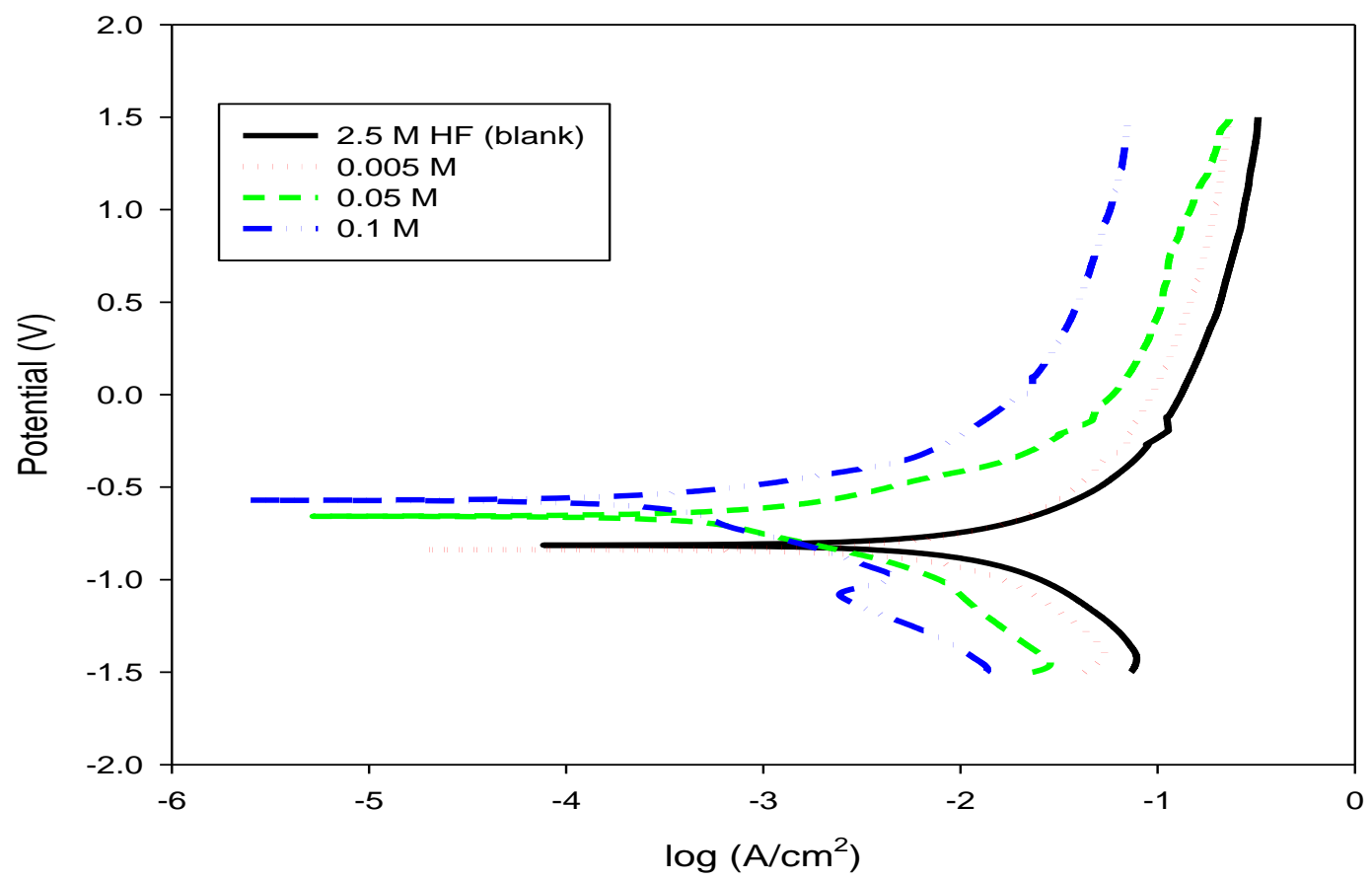

Fig 8:- Anodic and cathodic potentiodynamic polarization curves for pure Zinc in $2.5 \mathrm{M} \mathrm{HF}$ solution in the absence and presence of different concentration of Potassium chromate at room temperature

Effect of Potassium hydrogen phthalate and Sodium oxalate on the corrosion behavior of pure Zinc in hydrofluoric acid:-

Figures (9-10), show the effect of additive of different concentrations of potassium hydrogen phthalate and sodium oxalate on the polarization curves of pure zinc in $2.5 \mathrm{M} \mathrm{HF}$.

Table (4), illustrate the corrosion parameters for pure zinc in $2.5 \mathrm{M} \mathrm{HF}$ in the presence and absence of potassium hydrogen phthalate and sodium oxalate. From the results shown that, the inhibition efficiency (\% IE) values, reached to the maximum value $(98.4 \% \& 97.5 \%)$ at very dilute concentration of potassium hydrogen phthalate and sodium oxalate respectively. This was confirmed by scanning electron microscope (SEM) observation.

Fekry and Tamman [14], studied the corrosion behavior of magnesium alloy in presence of oxalate, and found that the corrosion rate increase with increasing oxalate concentration.

Table 4:- Corrosion parameters for the pure zinc electrode in $2.5 \mathrm{M} \mathrm{HF}$ containing different concentrations of potassium hydrogen phthalate and sodium oxalate at room temperature.

\begin{tabular}{|c|c|c|c|c|c|c|c|}
\hline Inhibitors & Concentration & $\mathrm{E}_{\text {corr. }} \mathrm{mV}$ & $\mathrm{i}_{\text {corr. }} \mathrm{mA} / \mathrm{cm}^{2}$ & $\beta_{\mathrm{a}}$ & $\beta_{\mathrm{c}}$ & $\mathrm{C} . \mathrm{R} \mathrm{mm} / \mathrm{y}$ & $\% \mathrm{IE}$ \\
\hline Blank (HF) & $2.5 \mathrm{M}$ & -818.0 & 2.2044 & 92.3 & -98.3 & 25.61 & --- \\
\hline & $5 \times 10^{-3} \mathrm{M}$ & -894.4 & 0.03314 & 96.7 & -102.8 & 0.385 & 98.4 \\
Potassium hydrogen & $5 \times 10^{-2} \mathrm{M}$ & -852.2 & 0.1522 & 92.4 & -65.2 & 1.769 & 93.0 \\
phthalate & $7 \times 10^{-2} \mathrm{M}$ & -911.1 & 1.2083 & 90.5 & -96.0 & 14.04 & 45.1 \\
\hline Sodium oxalate & $5 \times 10^{-3} \mathrm{M}$ & -314.7 & 0.0536 & 90.4 & -97.3 & 0.622 & 97.5 \\
& $5 \times 10^{-2} \mathrm{M}$ & -604.8 & 0.8716 & 91.8 & -173.4 & 10.12 & 60.4 \\
& $1 \times 10^{-1} \mathrm{M}$ & -743.8 & 1.427 & 95.4 & -104.9 & 16.59 & 35.2 \\
\hline
\end{tabular}




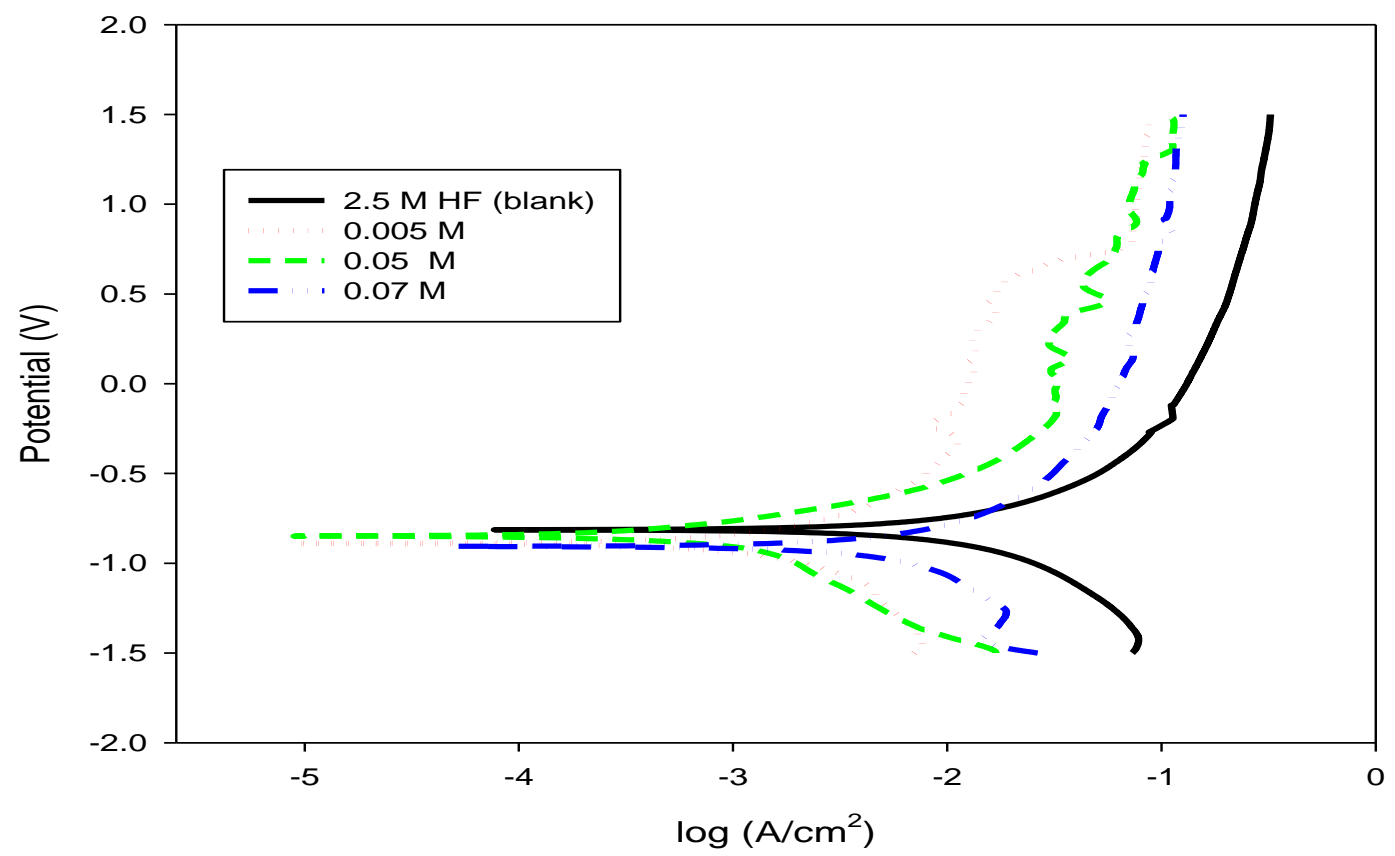

Fig 9:- Anodic and cathodic potentiodynamic polarization curves for pure Zinc in $2.5 \mathrm{M}$ HF solution in the absence and presence of different concentration of Potassium hydrogen phthalate at room temperature

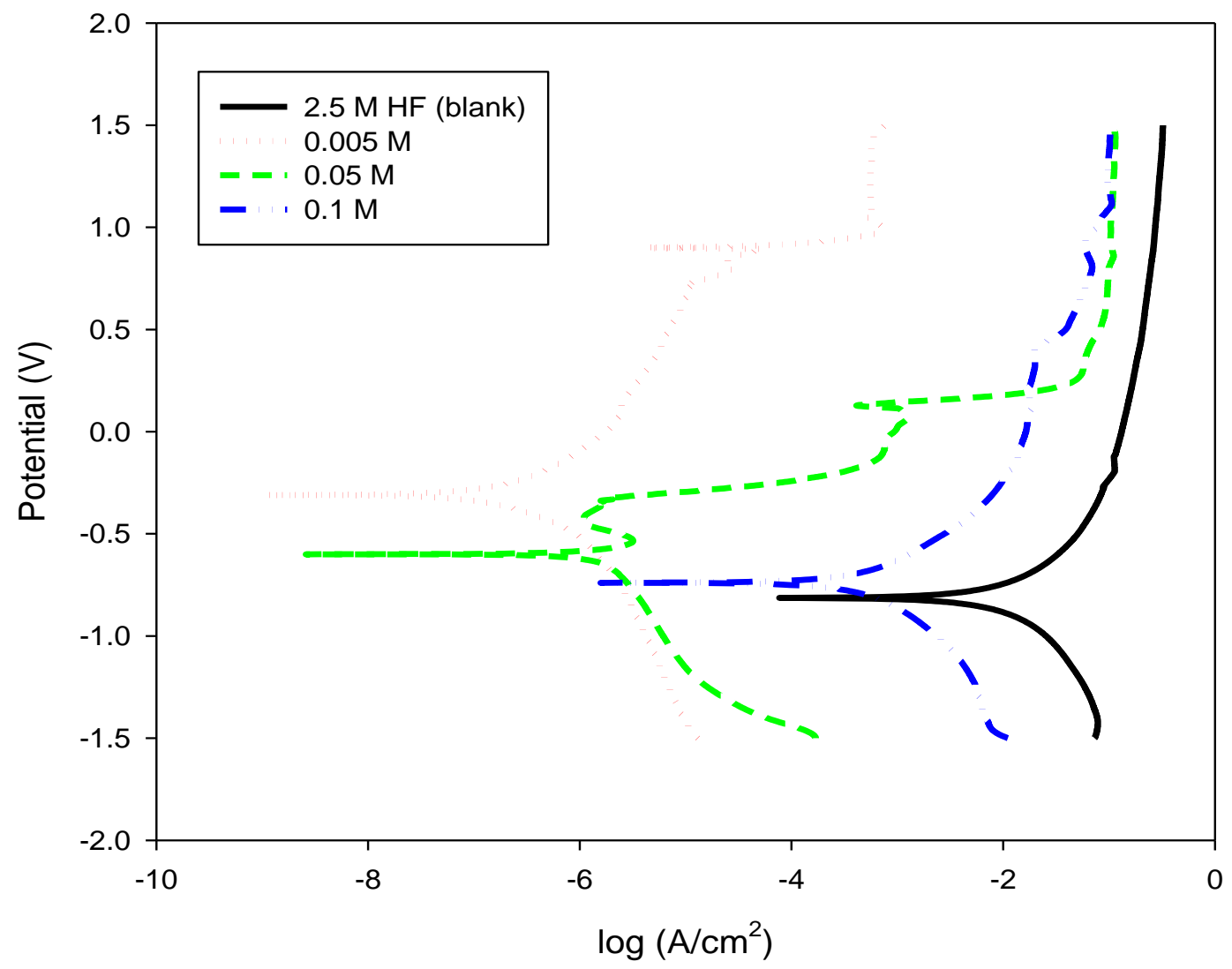

Fig 10:- Anodic and cathodic potentiodynamic polarization curves for pure Zinc in $2.5 \mathrm{M} \mathrm{HF}$ solution in the absence and presence of different concentration of Sodium oxalate at room temperature. 
Mechanism of Inhibition Action of Organic and Inorganic salts on pure Zinc in 2.5 M Hydrofluoric acid Zinc is thermodynamically unstable in the presence of water and aqueous solutions and tends to dissolve with the evolution of hydrogen in acid. This reaction often takes place extremely slowly when the zinc is very pure [15]. Feitknecht [16] observed that, various varieties of the hydroxide can be formed when zinc corrodes in aqueous solutions, that a protective coating of solubility comparable to that of $\varepsilon-\mathrm{Zn}(\mathrm{OH})_{2}$. The zinc hydroxide are amphoteric, dissolving in acid solutions to give zincic $\mathrm{Zn}^{++}$ion [15].

\section{- Zinc dissolution}

$\mathrm{Zn} \longrightarrow \mathrm{Zn}^{2+}+2 \mathrm{e}^{-} \quad$ reaction (2)

- Reduction of dissolved oxygen

$\mathrm{O}_{2}+2 \mathrm{H}_{2} \mathrm{O}+4 \mathrm{e}^{-} \longrightarrow 4 \mathrm{OH}^{-}$

hence, $\mathrm{Zn}^{2+}$ reacts with $\mathrm{OH}^{-}$to form zinc hydroxide near the $\mathrm{Zn}$ surface

$\mathrm{Zn}^{2+}+2 \mathrm{OH}^{-} \longrightarrow \mathrm{Zn}(\mathrm{OH})_{2}$

\section{- Metallic fluoride film formation}

In case of addition of HF, the metallic fluoride film can be formed [11].

$6 \mathrm{HF}+6 \mathrm{H}_{2} \mathrm{O}=6 \mathrm{H}_{3} \mathrm{O}^{+}+6 \mathrm{~F}^{-}$

$2 \mathrm{~F}^{-}+5 \mathrm{Zn}^{2+}+6 \mathrm{OH}^{-} \longrightarrow 2 \mathrm{ZnF}+3 \mathrm{Zn}(\mathrm{OH})_{2}$

Metallic fluoride film

\section{- Layer formation [17]}

For example in case of addition of Potassium dichromate as inorganic salt.

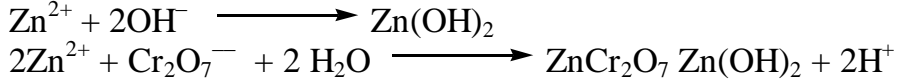

reaction (3)

reaction (4) reaction (5)

reaction (1)

\section{reaction (4)}

reaction (6)

\section{Morphological evaluation (Scanning electron microscopic (SEM) measurements):-}

Pure zinc is homogenous in microstructure as there is only one phase presented in accordance with another investigation [18]. SEM images show the evaluation of the pure zinc surface during the potentiodynamic polarization experiments from -1500 to $1500 \mathrm{mV} \mathrm{Ag}_{\mathrm{AgCl}}$. A photograph of the polished pure zinc surface is shown in figure 11 (a). The photograph shows the surface was uniform and free cracks.

A photograph of pure zinc surface after potentiodynamic polarization test in $2.5 \mathrm{M}$ hydrofluoric acid solution is shown in figure 11 (b), the photograph revealed that, the surface was strongly damaged and also some cracks were found [19] .

Figure $12(\mathrm{c}-\mathrm{e})$, shows the SEM photograph of the pure zinc in $2.5 \mathrm{M}$ hydrofluoric acid solution in presence of higher concentration (i) and lower concentration (ii) of (c) tri-sodium citrate, (d) potassium dihydrogen ortho phosphate and (e) potassium dichromate salts.

The results showed better corrosion resistance against zinc corrosion in the acid media.

Figure 13 ( $\mathrm{f}-\mathrm{g}$ ), shows the SEM photograph of the pure zinc in $2.5 \mathrm{M}$ hydrofluoric acid solution in presence of higher concentration (i) and lower concentration (ii) of (f) potassium hydrogen phthalate and (g) sodium oxalate salts.

The effect of the inhibitors on the morphology and prevention of the cracking corrosion is remarkable. It seems that from figure $13(\mathrm{f}-\mathrm{g})$, that corrosion decreased largely in the presence of these inhibitors and may be observed much dense film formed in case of lower concentration than that in case of higher concentration. 

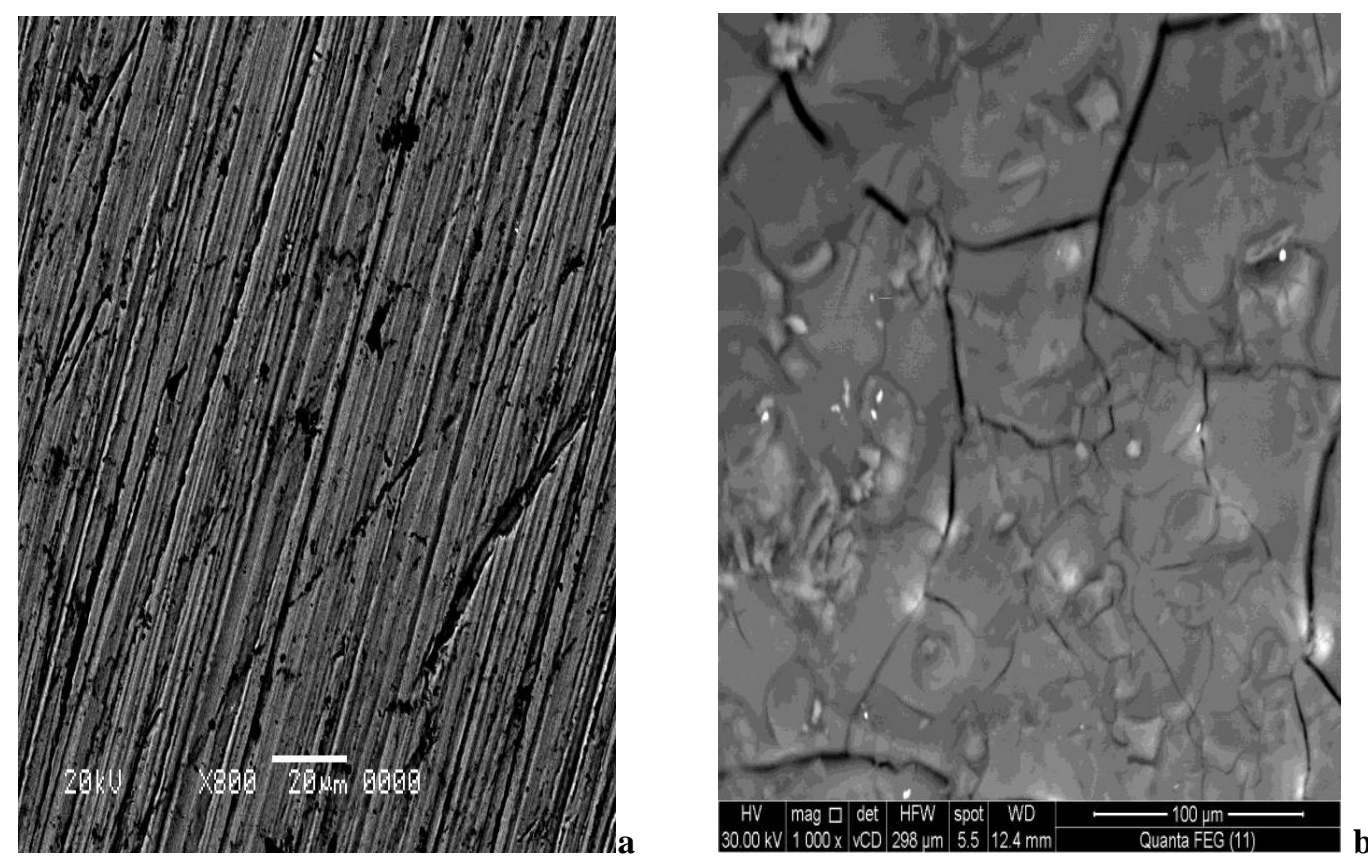

Fig 11:- Surface morphologies of (a) polished pure zinc surface, (b) and of pure zinc surface after potentiodynamic polarization test in $2.5 \mathrm{M}$ hydrofluoric acid solution without the addition of inhibitors.
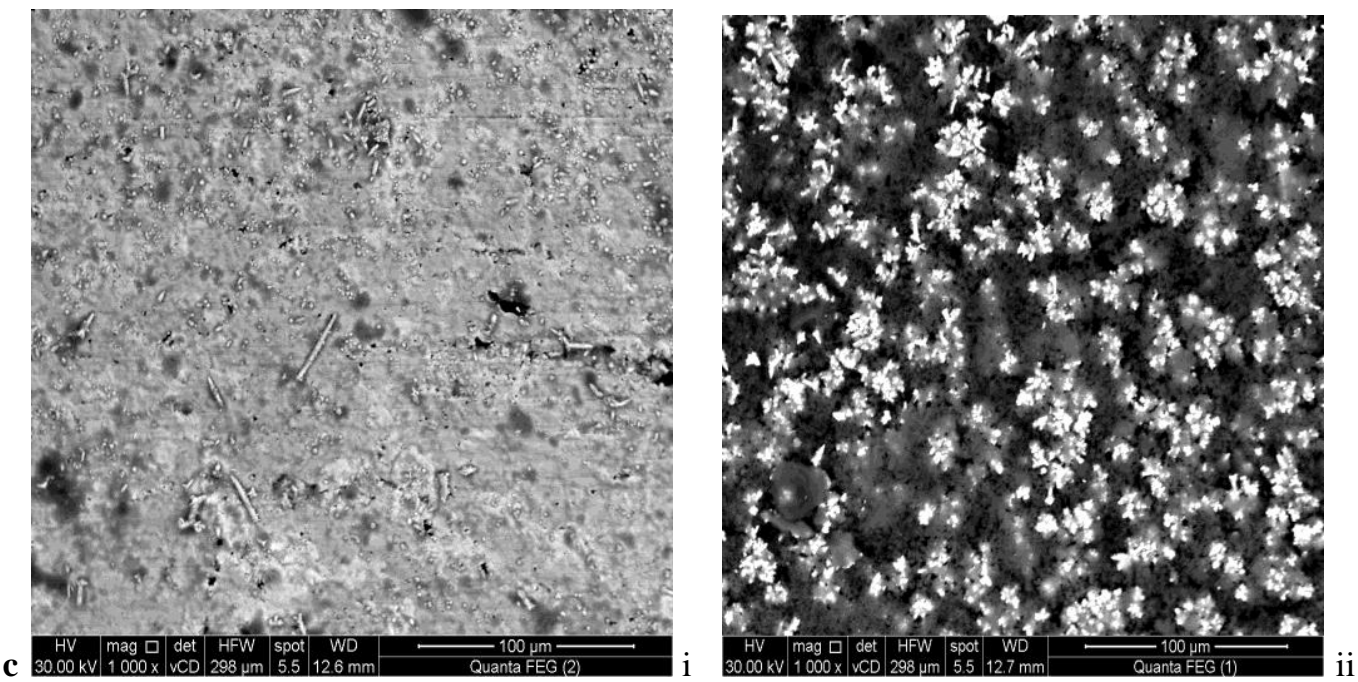

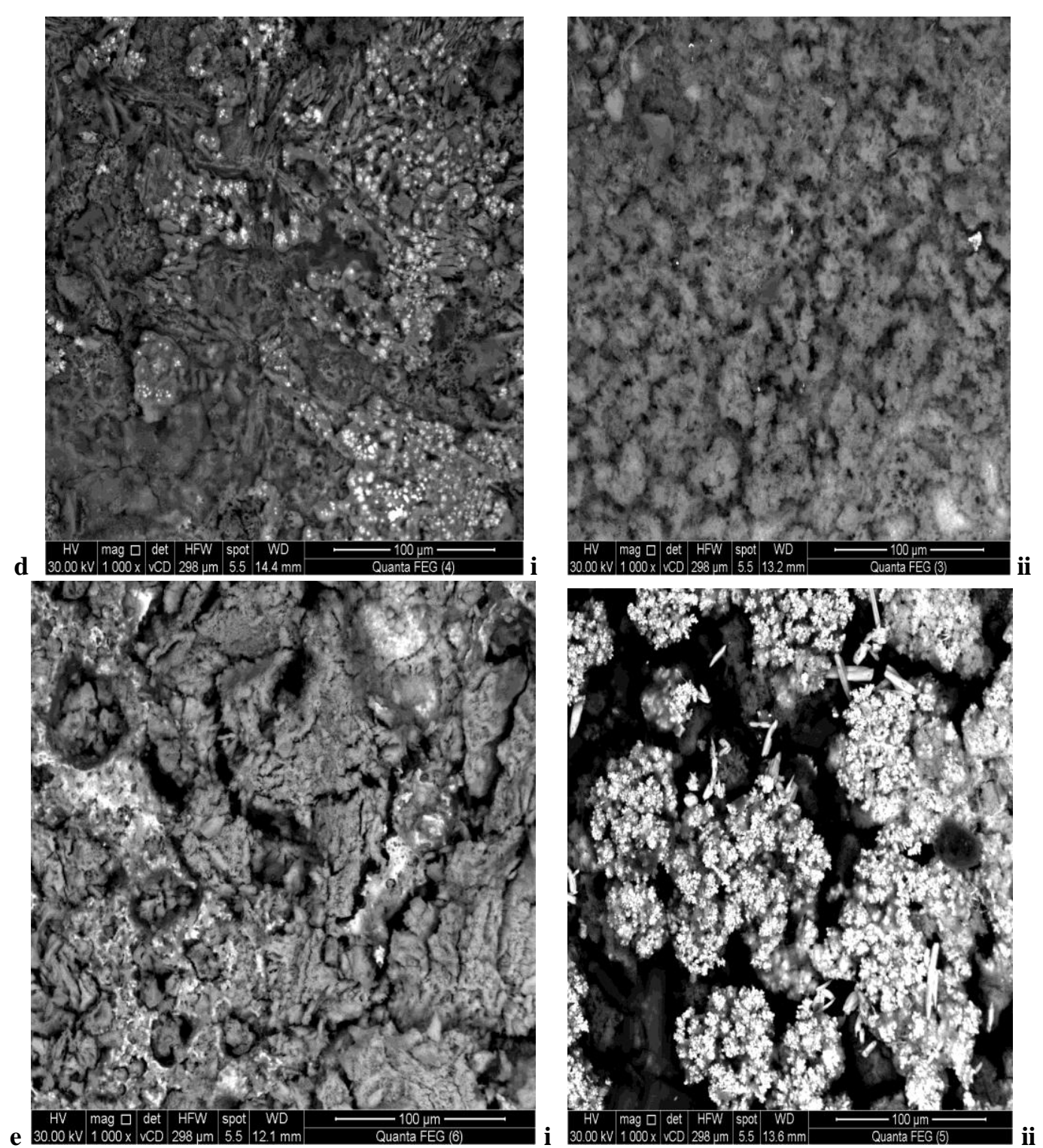

Fig 12:- Surface morphologies of the pure zinc in $2.5 \mathrm{M}$ hydrofluoric acid solution in presence of higher concentration (i) and lower concentration (ii) of (c) tri-sodium citrate, (d) potassium dihydrogen ortho phosphate and (e) potassium dichromate salts. 

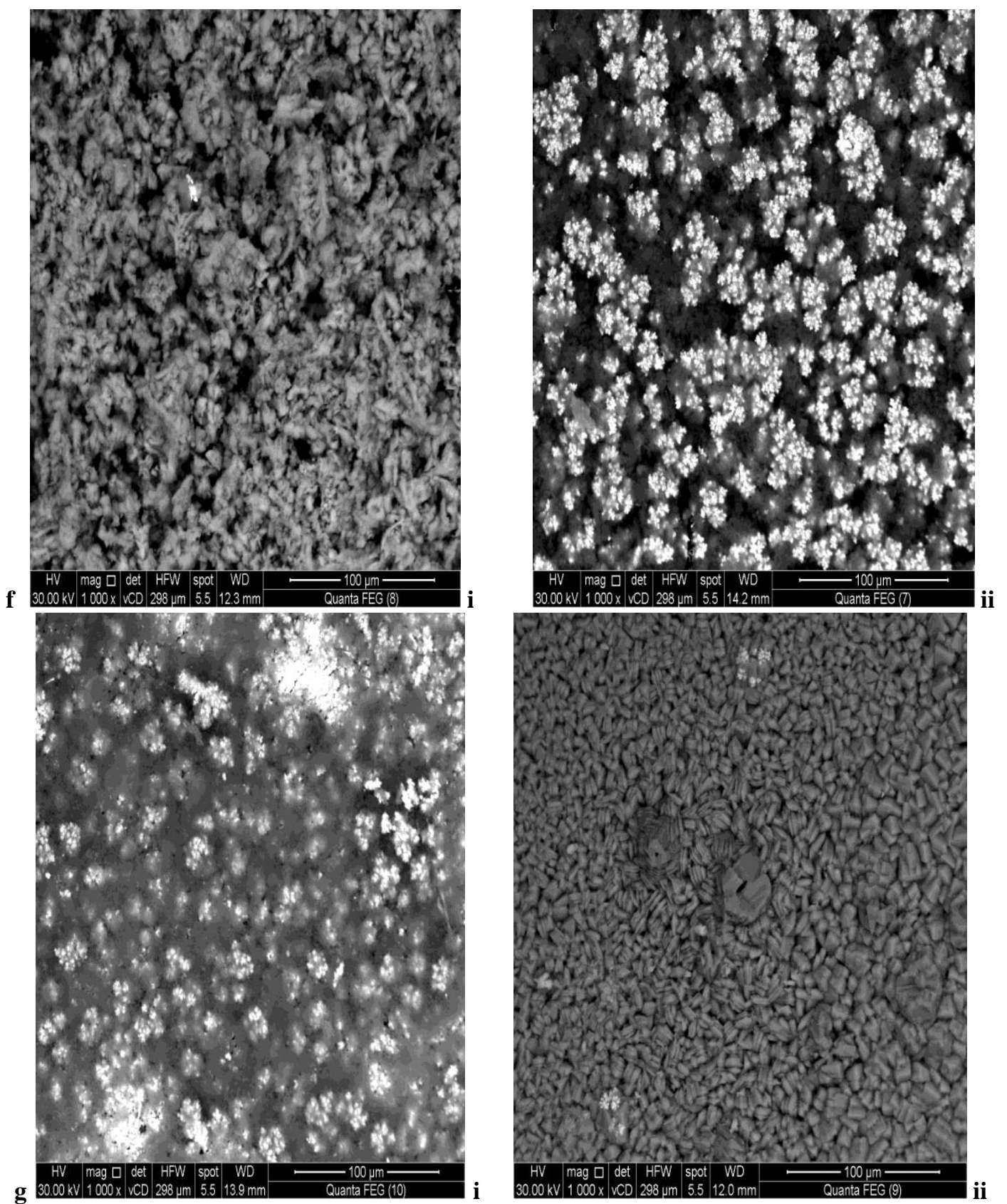

Fig 13:- Surface morphologies of the pure zinc in $2.5 \mathrm{M}$ hydrofluoric acid solution in presence of higher concentration (i) and lower concentration (ii) of (f) potassium hydrogen phthalate and (g) sodium oxalate salts.

\section{Conclusion:-}

The electrochemical behavior of pure zinc in $2.5 \mathrm{M} \mathrm{HF}$ solution containing different concentrations of different organic and inorganic salts was evaluated.

The inhibition efficiency was found to be maximum at higher concentration in case of tri- sodium citrate, potassium dihydrogen ortho phosphate and potassium dichromate salts while the maximum value of IE in another salts such as potassium hydrogen phthalate and sodium oxalate salts at lower concentration .

The SEM observations confirm the protection of pure zinc corrosion in $2.5 \mathrm{M}$ HF solution by different organic and inorganic salts. 


\section{References:-}

1. Q. Qu, C.W. Yan, C.N. Cao; Corrosion Sci., 44, 2789, (2002).

2. Q. Qu, L. Li, W. Bai, C.W. Yan ; Transactions of Nonferrous Metals Society of China, 16, 887, (2006).

3. D. A. Shifter ; Corrosion Sci., 47, 2335, (2005).

4. R.B. Rebak; ASM Hand book, volume 13B, Corrosion: Materials, Environment, Industries , (2004).

5. Pierre R. Roberge ; Hand book of Corrosion Engineering, Chapter 10, (1976).

6. G.Trabanelli ; Corrosion, 47 , 410, (1991).

7. A.A. Babich, G. I. Dremova, I.S. Pogrebova, Visn Kiiv ; Politekh Inst., Ser. Khim. Mashinobuduv. Tekhnol., 14, 109, (1991).

8. A. M. Avrunina, Z.M. ebrikova, Zh. V. Belaya ; I. P. Mordovchenko, Khim. Tekhno. Respub. Mezhvedom.Nauch. Tekh, 5b, 7, 123, (1967).

9. S.M. Abd El Haleem, A.A. Abdel Fattah ; Surface and Coatings Technology, 29 (1), 41, (1986).

10. P. Ayotte, M. Hebert, P. Marchand ; J. Chem. Phys., 123 (18), (2005).

11. https:// www.nickelinstitute.org/en/TechnicalLiterature/INCo\%20 Series/0443_CorrosionResistance of NiC.

12. L. W. Jones ; Corrosion and Water Technology for Petroleum Producers, Tulsa, Okla, Oil and Gas Consultants International, (1988).

13. M. Stern, A.L. Geary ; J. Electrochem. Soc., 104, 56, (1957).

14. A. M. Fekry, Riham H. Tammam ; Materials Science and Engineering B, 176, 792, (2011).

15. N. DE Zoubov, M. Pourbaix; Atlas of Potential/pH Diagrams, Pregamon, Oxford and Cebelcor (Center Belge D etude de la Corrosion) Reports Techniques, (1962).

16. W. FEITKNECHT ; M étaux et Corrosion, 23, 192, (1947).

17. P. Pokorny, P. Tej, P. Szelag ; METALURGUA, 55 (2), 253, (2016).

18. B. Zhang, H.B. Zhou, E.H. Han, W. Ke ; Electrochim. Acta, 54, 6598, (2009).

19. Xin-Yu YE, Min-Fang CHEN, Chen YOU, De-Bao LIU ; Fron. Mater Sci. China, 4 (2), 132, (2010). 